\title{
Regulatory and Biosafety Challenges for Vaccines
}

\author{
Fatemeh Nafian ${ }^{1 *}$, Simin Nafian², Babak Kamali Doust Azad
}

1. Department of Medical Biotechnology, Faculty of Medical Sciences, Tarbiat Modares University, Tehran, Iran

2. Department of Stem Cell and Regenerative Medicine, Institute of Medical Biotechnology, National Institute Genetic Engineering \& Biotechnology (NIGEB), Tehran, Iran

3. Department of Nano-Bioelectronics, School of Electrical and Computer Engineering, Tehran, Iran

\section{ABSTRACT}

The global regulatory plan for vaccines provides a unique opportunity to develop safe and effective ones with assured quality. Methods used by regulators address challenges of new products and technologies and also increase understanding of benefits and risks of existing products. First, the laboratory-based regulatory sciences evolve correlates of immunity and safety; or improve the product characterization and potency assays. Second, these sciences design clinical trial tools to analyze novel benefit-risk methodologies for vaccines, and standardize regulatory processes. The aim of the Global regulatory agenda is to transform current national efforts into a coordinated execution plan to support worldwide immunization goals. In the current article, it has been defined the role of regulatory science to improved access to effective vaccines, and identified gaps that could be addressed through that. Also, the challenges of implementing a regulatory agenda have been investigated, and proposed strategies to resolve these gaps. In this way, an appropriate agenda will enable regulators, academics and other stakeholders to work in a coordinated way to innovate in the regulatory processes in support of global immunization goals.

Keywords: Vaccine regulation, Vaccine qualification, Vaccine standardization, Clinical trials, Biosafety.

Received: 2019/05/20; $\quad$ Accepted: 2019/08/20; Published Online: 2020/03/14

\begin{tabular}{cl}
\hline Corresponding Information: & $\begin{array}{l}\text { Fatemeh Nafian, Department of Medical Biotechnology, Faculty of Medical Sciences, Tarbiat Modares University, Tehran, Iran. } \\
\text { Email: farshiddanesh@ricest.ac.ir }\end{array}$ \\
\hline C.) Copyright @ 2020 , This is an original open-access article distributed under the terms of the Creative Commons Attribution-noncommercial 4.0 International License which \\
permits copy and redistribution of the material just in noncommercial usages with proper citation.
\end{tabular}

Use your device to scan and read the article online

Nafian F, Nafian S, Kamali Doust Azad B. Regulatory and Biosafety Challenges for Vaccines. Iran J Med Microbiol. 2020; 14 (1):17-29

Download citation: $\underline{B i b T e X}$ | RIS | EndNote | Medlars | ProCite | Reference Manager | RefWorks

Send citation to: $\Leftrightarrow$ Mendeley 2 Zotero $\dot{B}$ RefWorks

\section{Introduction}

A global regulation can provide unique opportunities to develop vaccine quality, biosafety and efficacy that have been investigated in a limited target population. It is a life-threatening step since the vaccine must protect healthy people and children against a specific disease that they may never get. The global regulatory agenda transforms a current national effort into an organized execution plan to support worldwide immunization goals. The US Food and Drug Administration (FDA) has established a program called Post-Licensure Rapid Immunization Safety Monitoring (PRISM) to improve post-market in situ monitoring based on data from the health and medical service centers $(1,2)$. Another international program has been undertaken in Europe by VAESCO Consortium (Vaccine Adverse Events Monitoring and Communication) to address specific regulatory and compliance challenges in new products and technologies, as well as the benefit-risk assessments of existing vaccines (3). New vaccines such as recombinant vaccines cannot be disinfected and purified by conventional methods and their validations are entirely dependent on the ability and 
reproducibility of bioassays. The biological resources for vaccine production including eggs, mammalian cells or bovine fetal serum are susceptible for contamination. The important features of vaccines to trigger immune response can be enhanced by advancing the quality control of raw materials and diagnostic assays for infectious agents (4).

\section{Materials and Methods}

Conventional production processes and their monitoring topics are well-known for viral fermentation and yeast recombinant DNA-based techniques are welldefined (13). However, new vaccines have been produced by other systems including insect cells or live insects (14), transgenic animals or plants, or new cell cultures (15). These systems need specific regulations for the detection of tumorigenesis residual compounds or unfavorable infections (16). Regulatory authorization is the starting point in the production cycle of approved vaccines. When the product is introduced to the market, tests and protocols may change. Any changes to the production process or administration protocol need to be reviewed and approved by the National Regulatory Authorities (NRA). Benefit-risks will be revised and adjusted by monitoring systems, depending on the amount of approved changes or difference between biosafety and efficacy pre- and post-marketing profiles. Laboratory-based sciences design standardized regulatory processes and clinical trials to analyze novel benefit-risk procedures for vaccines. Monitoring guidelines of new production technologies assess immune responses against edible vaccines, or potential growth of insect viruses in humans or animals, alternative antigen phenotypes in new cell cultures with the positive or negative immunogenic effect or residual DNA from host cells. Novel approaches have improved quality and biosafety controls rather than traditional methods. Mass spectrometry, nuclear magnetic resonance (NMR) and circular dichroism (CD) are useful to investigate the final structure of highly glycosylated protein vaccines and their stability, as well as undesirable substances such as bacterial polysaccharides (19). Highthroughput sequencing, "next generation sequencing (NGS)", provides high accurate information about final vaccines, intermediates, substrates $(20,21)$, or unknown infectious agents for example in a rotavirus vaccine (porcine circovirus) (22-24). By whole genome sequencing, NGS will investigate the genetic stability of viral vaccines containing high mutation rates (such as RNA viruses) (25). Antibody titration can be used to evaluate immunization efficacy and biosafety of new vaccines, adjuvants, or viral strains in seasonal vaccines such as influenza $(28,27)$. However, it is not sufficient to evaluate intracellular pathogens vaccines with cellular immune responses such as HIV, Tuberculosis (TB), or malaria (29).

\section{Results}

The global regulation agenda conducts clinical trials on a large number of healthy volunteers, especially infants and children, for more accurate standardization than other medical products. The regulatory process must be validated for specificity and sensitivity in an international agreement. Development of sensitive and specific assessments are very valuable to predict allergic reactions to vaccine formula or side effects in subpopulations, especially at-risk populations (such as infants). Vaccine biosafety can be improved by providing guidance for at-risk populations to quality control of essential substrates such as human or animal plasma, avoiding transport of infectious compounds; using carefully attenuated immunizations, evaluating toxicity of adjuvants, removing byproducts, and replacing live hosts with tissue cultures for specific vaccines. The number of phase 3 trials and approval time for a new lifesaving vaccine should be increased in the absence of a specific biosafety hypothesis for at-risk populations (30, 31). The amount of information required for production stages can be simulated by mathematical modeling and risk predicting $(32,33)$. In high-risk areas for a disease, people are at greater risk for early vaccination especially for diseases that have no treatment. It seems that further data for the post-market stage give high quality reports quickly and accurately. Reporting systems also play an important role in detecting adverse reactions to vaccine in developing countries that may not have access to electronic medical data. Reports require clinical evaluations as a "case series" to identify irrational patterns (35). However, perfect analysis of reported side effects remains a challenge despite advanced data mining (34). Artificial intelligence can summarize a great deal of information using a variety of algorithmic and statistical methods to obtain similar reports and expert reviews $(36,38,39)$. Some successful websites provide public health information about infectious diseases by the least time and cost including "HealthMap" (http://www.healthmap.org/en/) and "Google flu trends" (https://www.google.org/flutrends/about/). Of course, there is a better search opportunity by the epidemics of mobile phone and the like devices. Multivariate criteria decision-making analysis (MCDA) can theoretically be useful to standardize the evaluation of vaccine's benefit-risks in the global guideline as a quantitative model (40). This includes a risk matrix and an uncertainty matrix to visualize key effects for benefitrisk decision making. MCDA facilitates both monitoring and decision-making processes in more complex situations for example multiple contrast effects. By receiving new data, this model will be updated to show alterations in the benefit-risk balances. 


\section{Discussion}

The appropriate agenda will enable regulators, scientists and stakeholders to work in a coordinated monitoring for global immunizations. Regulatory sciences play important roles in improving biosafety monitoring and investigating strategies to effectively deal with remaining challenges. Vaccine biosafety can be developed by reducing animal use; developing new vaccine evaluations; and verifying high-throughput assays. New approaches to the "success or failure" boundaries of existing experiments must be validated in research laboratories before being approved for regulatory guidelines. The use of samples with different formulation and production process can influence the results. Existing vaccines or even failed ones should be available for new evaluative tests. The creation of one or more international sampling sources provides a mandatory strategy to support global guidelines. WHO partners are expected to mediate the international community to facilitate sample storage and exchange $(48,49)$. In the past, comprehensive vaccine safety assessments were carried out by major vaccine manufacturers in the United States and the European Union. Currently, the capacity of developing countries has been demonstrated to produce and evaluate its vaccine biosafety, which globally prevents concerns and assures successful vaccinations. However, low-income countries lack the technical resources for accurate biosafety regulation, where other medical problems are mistakenly attributed at the time of vaccination. Therefore, an international guidance by the WHO is essential for the regulation of adverse and rare vaccines reactions in these regions (53).

\section{Acknowledgment}

We would like to thank Dr. Rasaie, who helped us to design this article.

\section{Conflict of Interest}

Authors declared no conflict of interests. 


$$
\begin{aligned}
& \text { مجله ميكروبشناسى يزشكى ايران }
\end{aligned}
$$

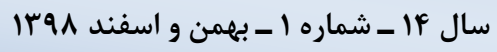

$$
\begin{aligned}
& \text { Journal homepage: www.ijmm.ir }
\end{aligned}
$$

\title{
جالشهاى نظارتى و ايمنىزيستى واكسنها
}

\section{فاطمه نافيان*'، سيمين نافيان ‘، بابك كمالى دوست آزادّ}

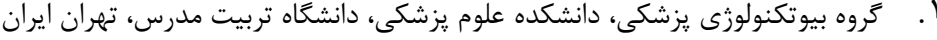

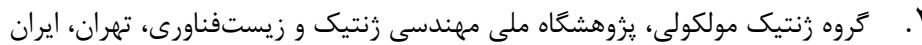

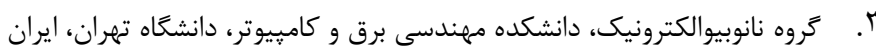

جكسيل

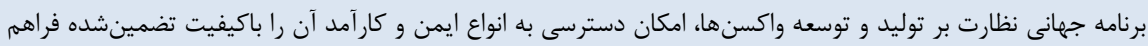

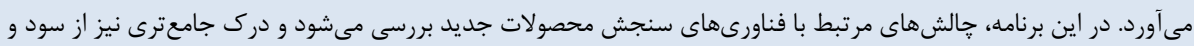

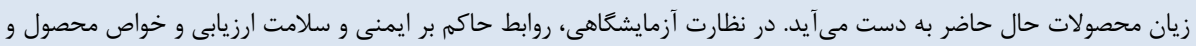

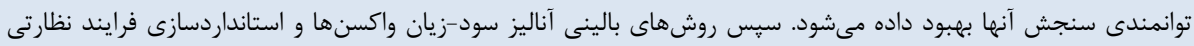

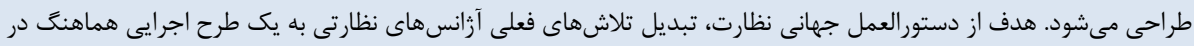

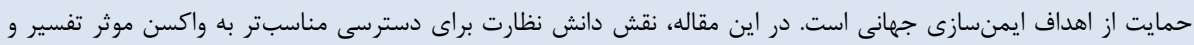

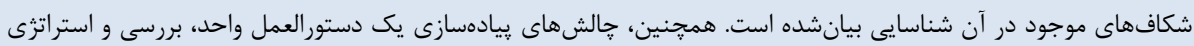

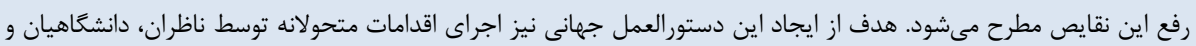

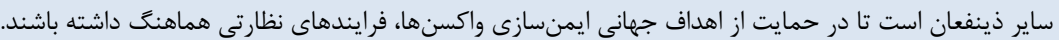
كليد وازهها: نظارت بر واكسن، كيفيت واكسن، استانداردسازى واكسن، آزمايشهاى بالينى، ايمنى زيستى

كبى رايت (C) مجله ميكروب شناسى بزشكى ايران: دسترسى آزاد؛ كيى بردارى، توزيع و نشر براى استفاده غيرتجارى با ذكر منع آزاد است.

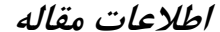

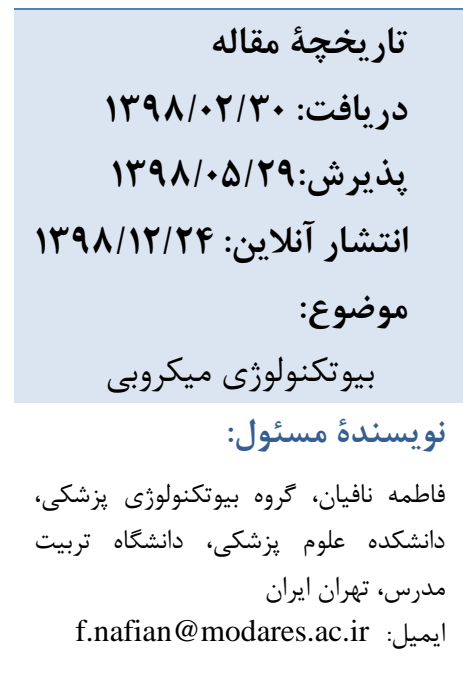

مقلدمه

زنتيك جمعيتهاى انسانى وجود دارد كه ممكن است در آنها

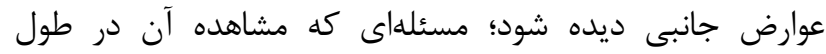

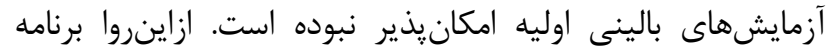
Post-Licensure Rapid Immunization Safety ) PRISM Monitoring )، توسط FDA راهندازى شد تا بر اساس دادههاى مركز خدمات درمانى و يزشكى، با روش نظارت در زمان اجرا، تلاش

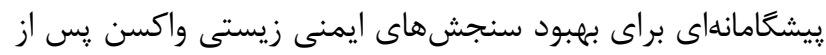

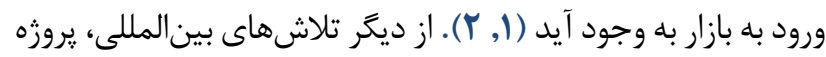

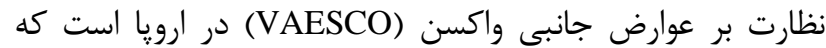
يتانسيلى براى بررسى جهانى سلامت واكسيناسيون محسوب

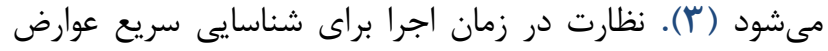

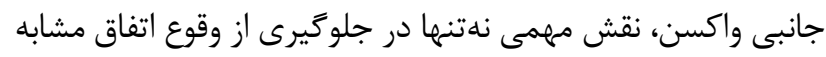

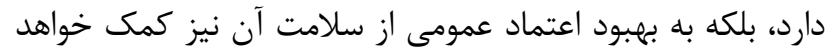

نظارت باكيفيت بالا، بر اساس يزوهشهاى بنيادين حداقل در

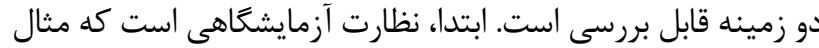

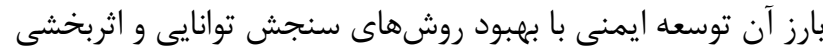

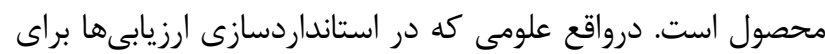
اهداف نظارتى بهكار كرفته مى شوند. دوم، دانش توسعه ابزارهاى بالينى براى آناليز ريسك تصميم گيرى و طرح روشهاى جديد

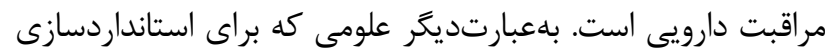

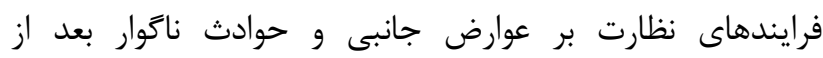
ايمنسازى، طرحهاى ابتكارى مى مهد. علم نظارت بلهور كلى

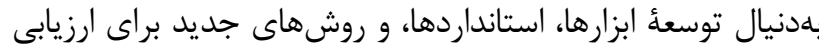

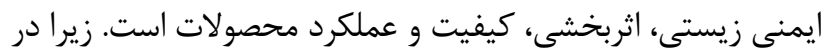
زمان تصويب واكسن، سلامت و اثربخشى بالينى بر بايه جمعيت إنى نسبتا كوجكى كذاشته مىشود كه هدف واكسيناسيون هستند. درحالى كه در هر برنامة جامع واكسيناسيون، سطح وسيعى از تنوع 


\section{ץ-ا.ـتوسعه روشهاى نوين براى ارزيابى واكسنهاى

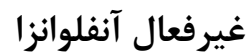

ويروس آنفلوانزا ازنظر زنتيكى و آنتىزنيك با فرايند تدريجى

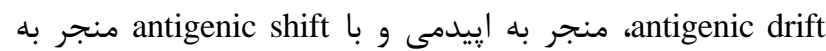
ياندمى ناكمانى و جشمخير مى شود. اين بدان معنى است كه در زمان

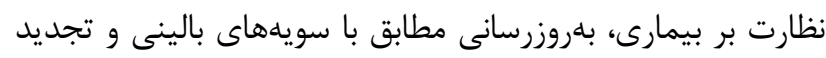

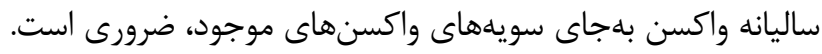
اين در حالى است كه تلاشها براى سادهسازى فرايند توليد

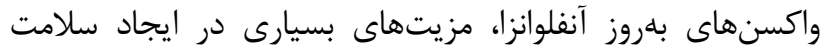

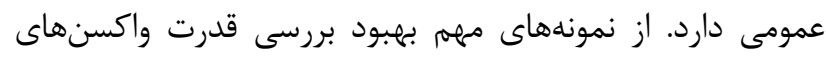

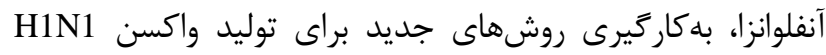

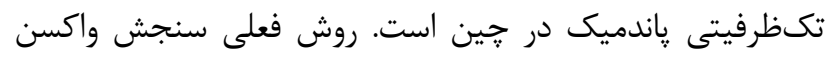
آنفلوانزاى غيرفعال، روش Single Radial Diffusion

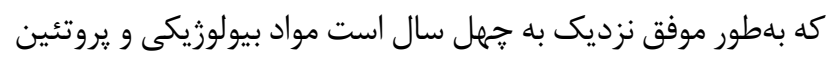
HA واكسن را اندازهيرى مى كند. اين روش ايمنولوزيك به موادى بنى

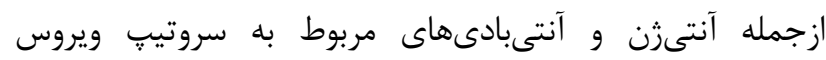

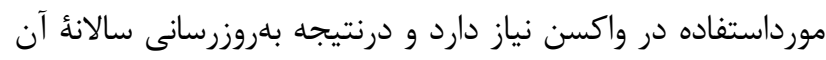
يك فرايند زمانبر است.

توليد آنتى سرم مرجع يروتئين HA معمولا شامل هضم

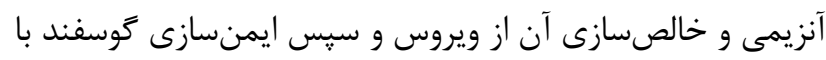

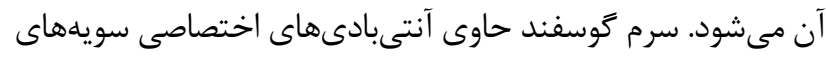

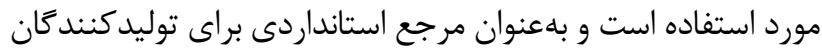

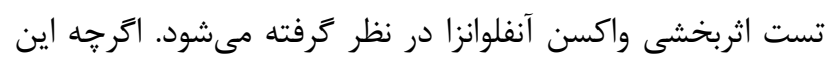
رويكرد براى توسعة آنتىبادىهاى ضد HA معمولا موثر است، مواردى وجود داشته است كه در آن ويزگكىهاى خاصى از برخى

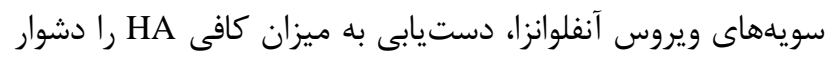

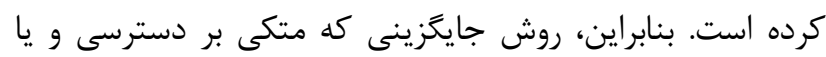
تخليص HA براى ايمنىزايى نباشد، بايستى توسعه يابد. در اين

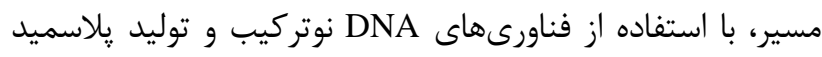

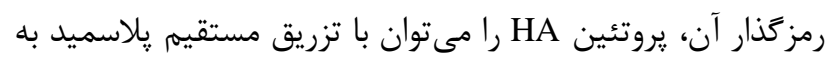

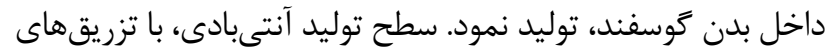
متوالى وكتور ويروسى مهندسىشده با HA همان سويه واكسن

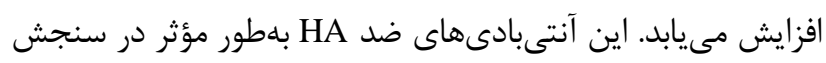

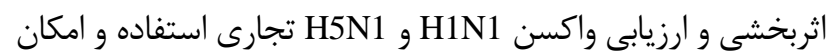

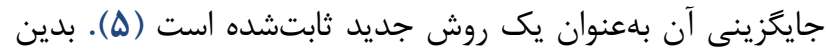

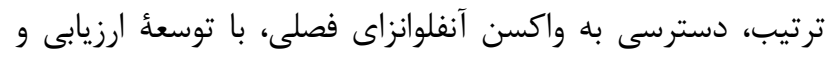

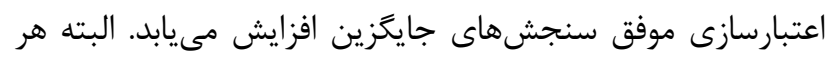

در اين مطالعه، به بررسى هالشهاى ييشرو كنترل كيفيت

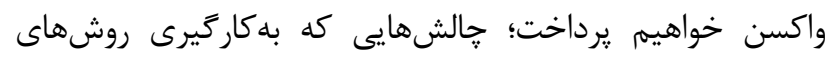

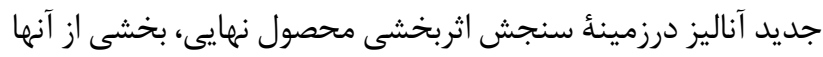
را برطرف نموده است. از آنجاكه واكسيناسيون براى افراد سالم و و معمولا كودكان انجام مىشود تا در برابر بيمارى هايى محافظت شوند

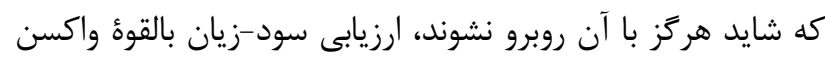

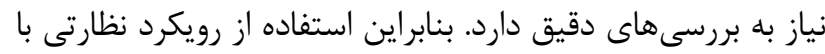
سطح : ايين، خطر بسيار زيادى دارد. ازاينرو، باوجود منفعت بيشتر

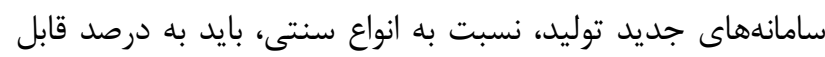

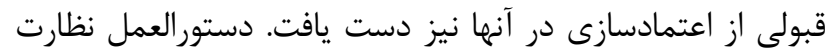
جهانى واكسنها، به بررسى محصولات، فنآورىهاى توليد و

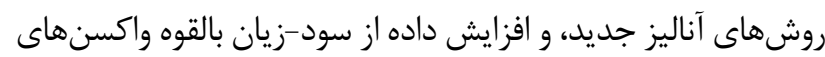

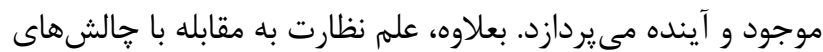
توسعه علمى و تجارى واكسن كمك مى كند.

\section{1. جالشهاى بيشرو در مسير بررسى كيفيت واكسنها}

به دلايلى، بررسى كيفيت واكسنها براى اطمينان از ايمنى و

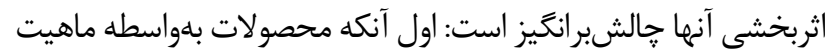
زيستى خود از يِيجيدگى و تنوع بالايى برخوردند. از طرفى منابع

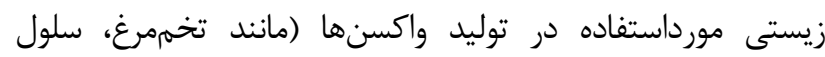

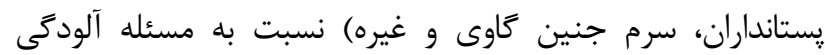
آسيبيذير هستند. بسيارى از واكسنها ازجمله واكسنهاى نوتركيب) را نيز نمىتوان با روش هاى معمول براى تركيبات شيميايى،

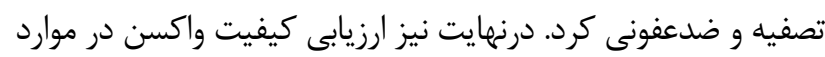
زيادى متكى بر قدرت و تكراريذيرى سنجش زيستى (مانند جالش

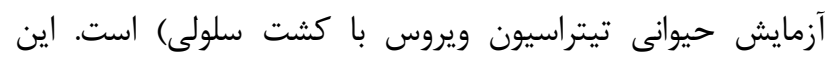

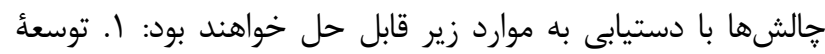
روشهاى تحليلى و نيز سنجشهاى تشخيصى مناسب و ييشرفته

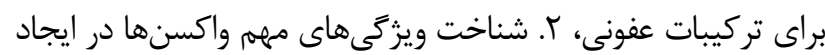

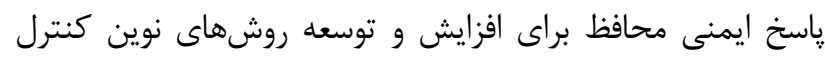

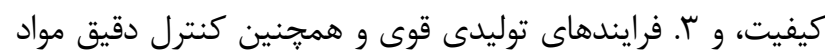
اوليه بهعنوان بخشى از ارزيابى براى اطمينان از كيفيت (براى مثال

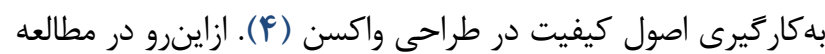

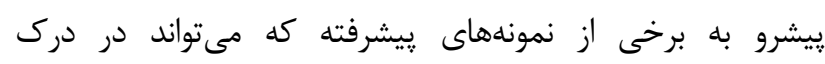
دستورالعمل جامع نظارت مههم باشد، اشارهشده است. 


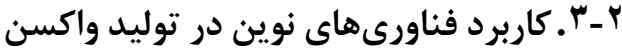

سيستمهاى رايج توليد واكسن شامل تخمير و رشد ويروسها

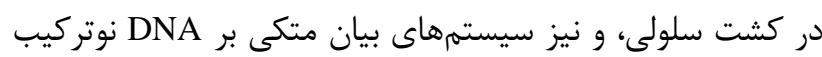
در مخمرها، بهطورمثال، به خوبى شناخته شدهاند و مسائل نظارتى

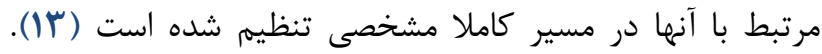

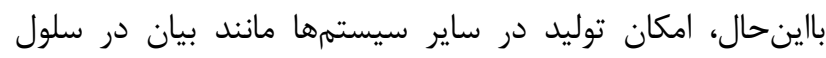

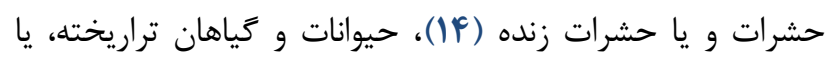
كشتهاى سلولى جديد، مانند سلولهاى تومور انسانى، وجود دارد (1) (1) البته تمامى اين سيستمها، مسائل نظارتى خاص خود را مانند

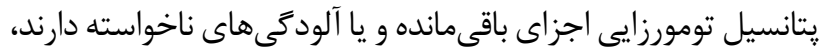

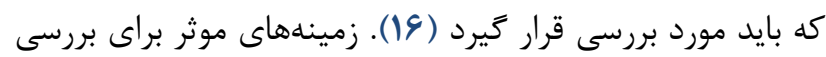

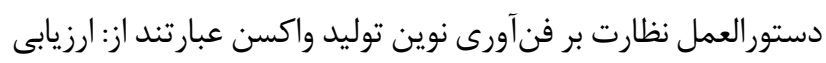

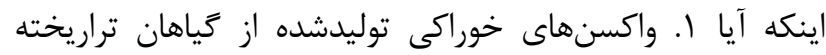

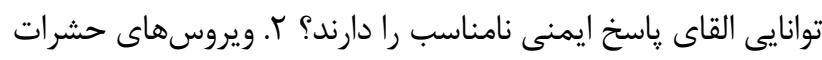

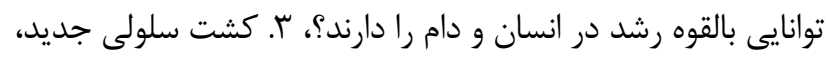

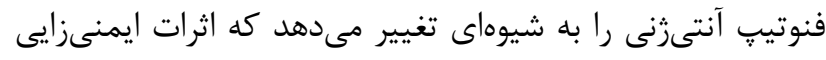

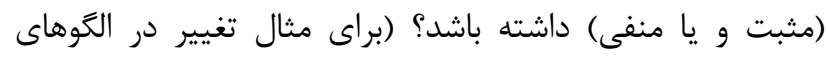

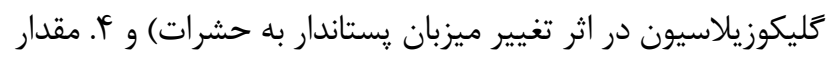

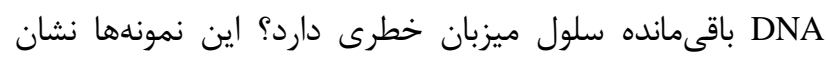

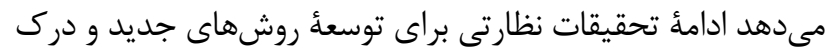

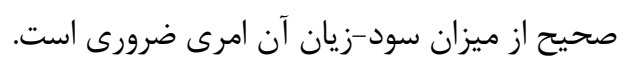

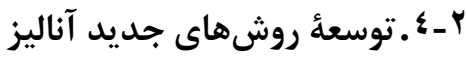

روشهاى جديد آناليز بلويزه درزمينأ سنجش اثربخشى منجر به كنترل و ارزيابى بهتر كيفيت محصولات نهايى مىشود.

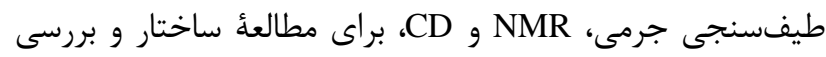
حضور مواد جانبى در محصول و پايدارى يروتئين، مفيد هستند و بدين ترتيب مكمل روشهاى بيولوزيك كلاسيك محسوب مىشوند

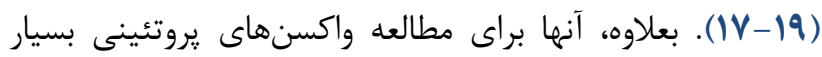

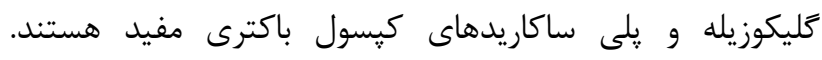

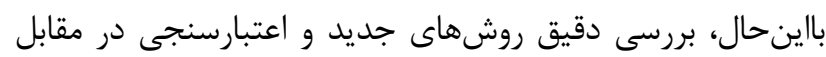
روشهاى سنتى، قبل از تصويب براى اهداف نظارتى ضرورى است. توالىيابى با توان بالا ("نسل جديد" توالى ايابى) براى ارائئ اطلاعات

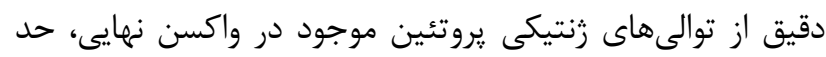
واسطها، يا مواد خام مورداستفاده در طول توليد، ابزار بسيار

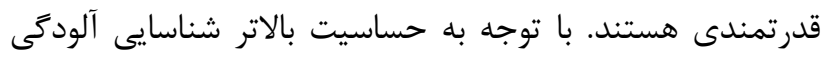

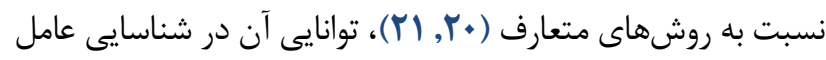
عفونى ناشناخته در يك واكسن اثباتشده است (بهطور مثال در
روش جديد نياز به بهبود روش فعلى براى اندازمخيرى آنتىزن و

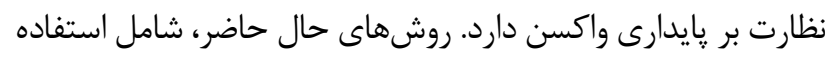
از موادى است كه واكنش متقاطع با طيف وسيعى از كونههاى

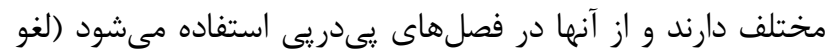

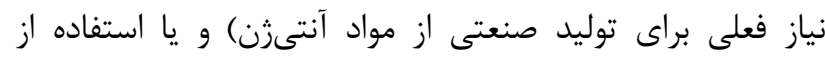

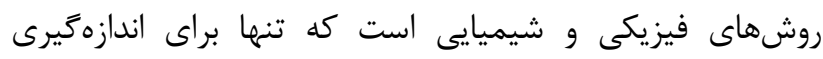

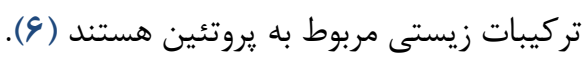

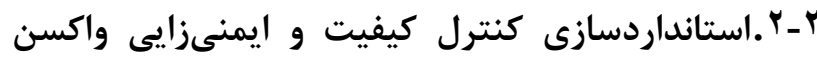 \\ جديد انتروويروس VI T)}

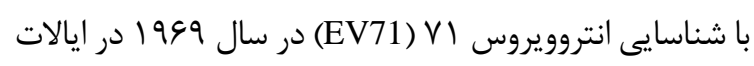

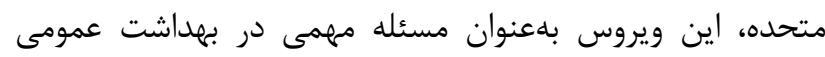

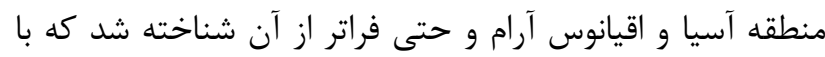

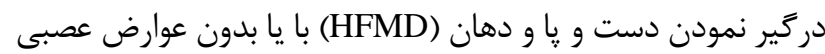

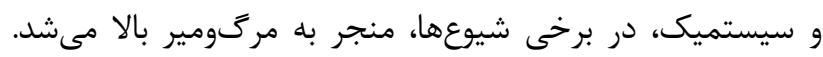

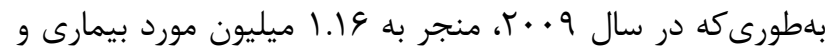

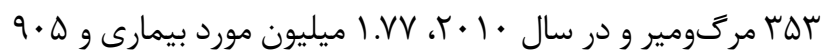

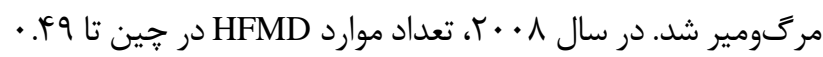

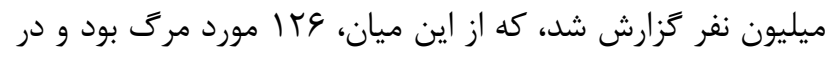

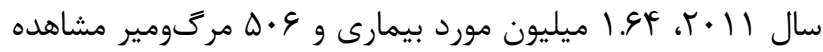

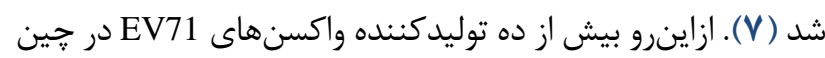

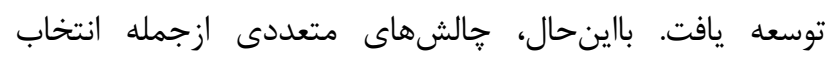
سويههاى واكسن، سنجش ايمنىزايى و فقدان استانداردهاى ملى و إنى

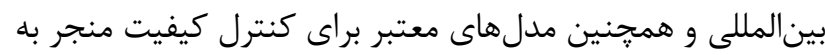
ييشرفت آهسته در توليد اين واكسنها شده است. البته، براى غلبن مائه بر برخى از اين خالشها، خصوصيات زنتيكى و آنتىزنيك سويههاى

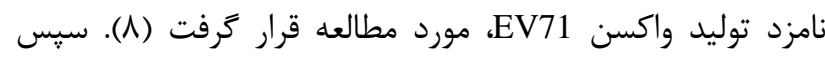

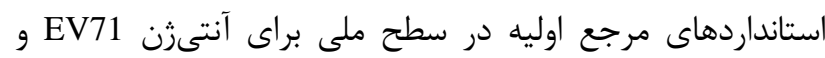

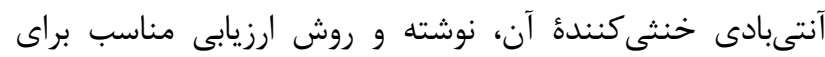

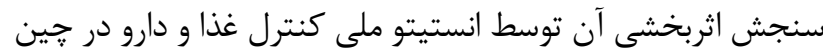
(NIFDC)

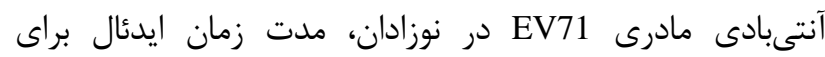

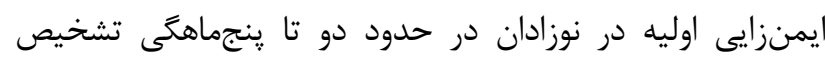

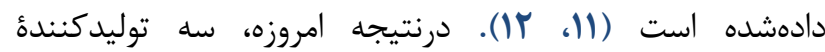
واكسنهاى EV71 وارد فاز r آزمايشهاى بالينى شدهاند. باين حال،

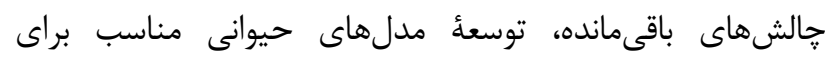
مكانيسم بيمارىزايى و حفاظت است. 


\section{r. دستورالعمل جهانى نظارت بر ارزيابى بالينى واكسنها}

ـ ـ ـ ـ استانداردسازى روش ارزيابى ياسخهاى ايمنى واكسنها

ارزيابى پاسخهاى ايمنى در برابر واكسنهاى موجود آنفلوانزا

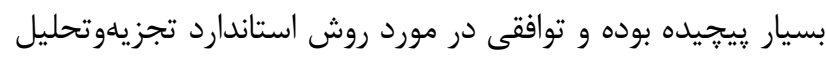

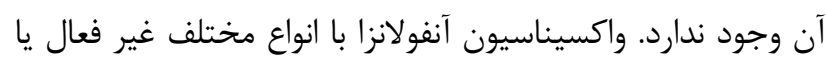

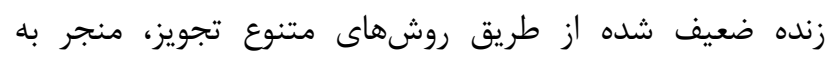

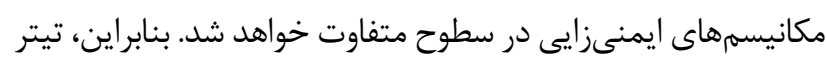

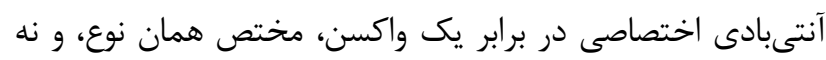

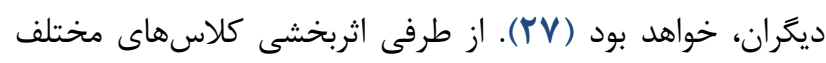

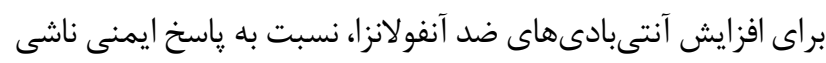

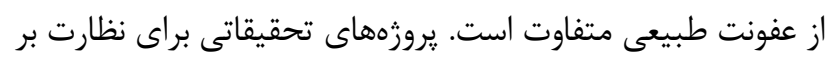

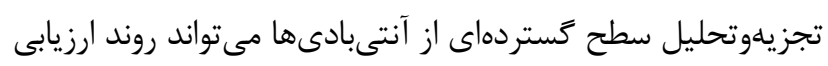

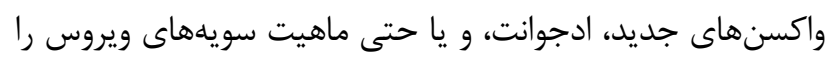

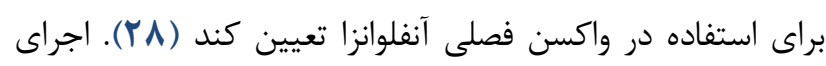

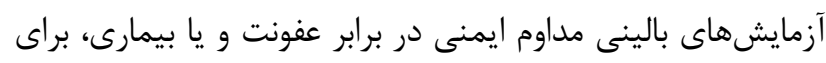

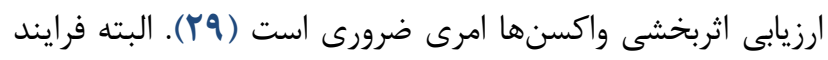

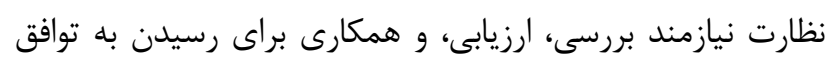
بينالمللى بر روى صحت، وضوح و حساسيت اين طرحها است.

\section{צ-r. توسعه ايمنى زيستى در واكسنها}

در بررسى واكسنها همواره براى ارتقاى سلامت اين

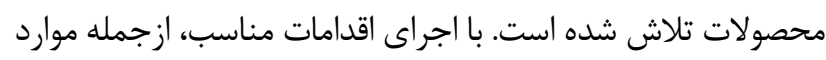
زير، به اين مهمر پاسخ داده شده است:

م حذف عوامل جانبى واكنشيذير واكسن (كاهش ناخالصىها تا كمتر از سطحى كه اثرات بالينى بلوجود آورد).

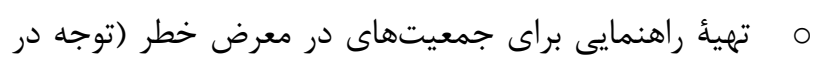

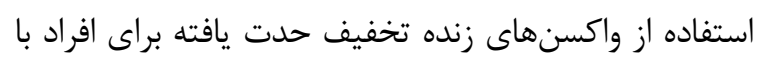

$$
\text { سيستم ايمنى سركوب شده). }
$$

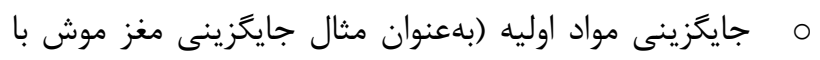

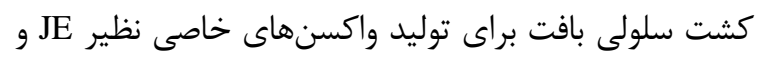

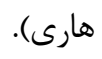

o كنترل دقيق مواد اوليه ضرورى، مانند سلول و يا پإسماى

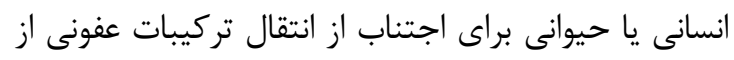

$$
\text { طريق واكسن. }
$$

اين رويكردها و ديكر اقدامات نظارتى در بهحداقلرسانى

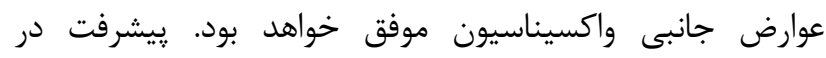

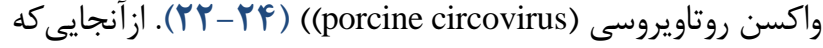
اين روش اطلاعات توالى رنوم يك جمعيت را ا رائه مى دهد، مى تواند براى بررسى ثبات زنتيكى واكسنهاى ويروسى حاونى حاوى اسيدهاى

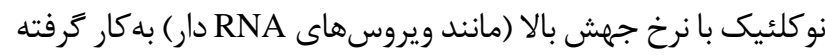

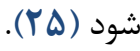

\section{r.دستورالعمل جهانى نظارت بر ارزيابى غير بالينى واكسنها r- إ. ارزيابى ادجوانت (adjuvant) واكسنهاى جديد}

واكسنها، مشتقات آنتىزنى خالص يا نوتركيب هستند كه

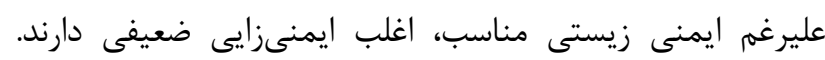

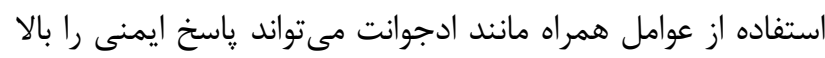

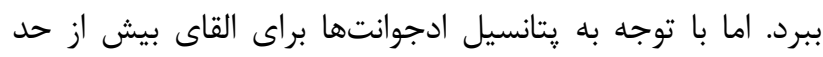

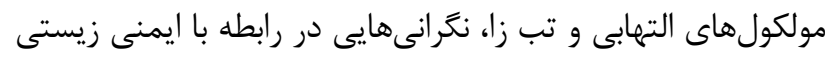

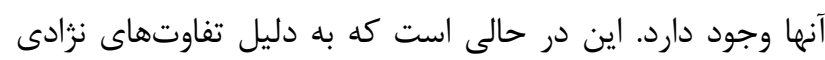

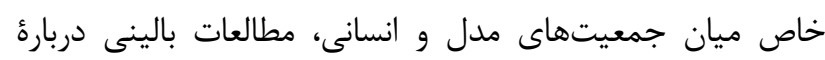

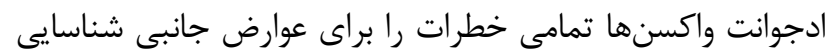

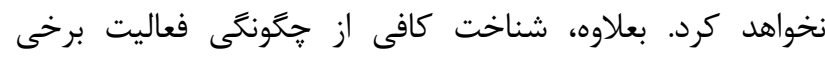

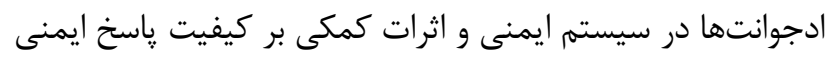

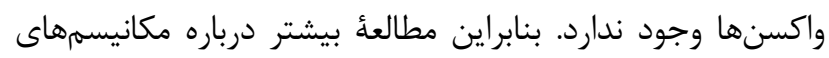

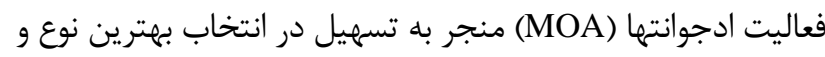

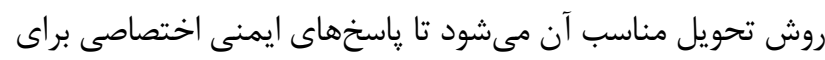

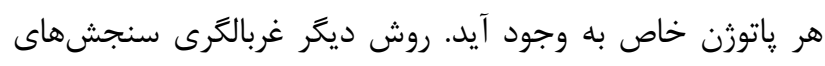

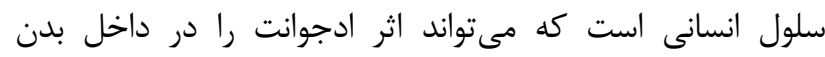

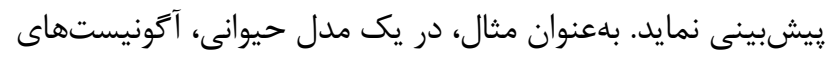

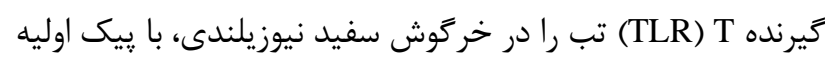

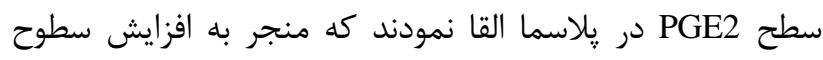

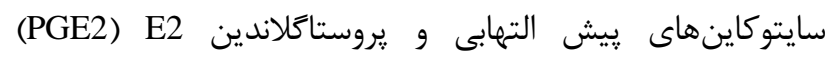

مونوسيتهاى شده بود (Y) (Y).

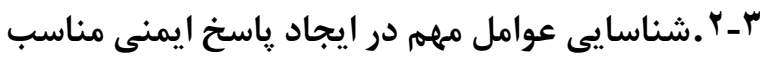

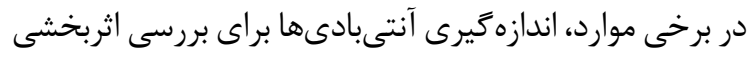

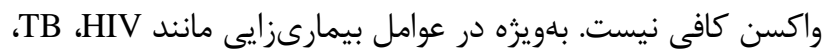

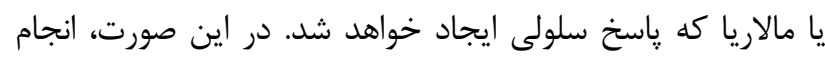

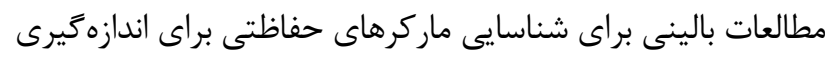

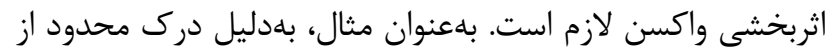

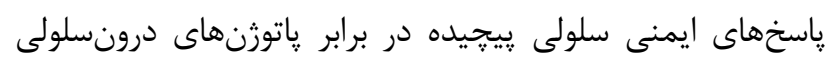

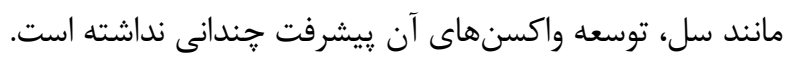


†+. دستورالعمل جهانى نظارت بر واكسنها بعد از ورود به

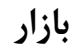

هـ ا. لزوم بهبود نظارت بر ايمنى زيستى واكسن يس از

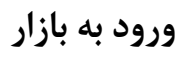

وجود سيستمهايى براى بررسى سريع و دقيق ايمنى زيستى

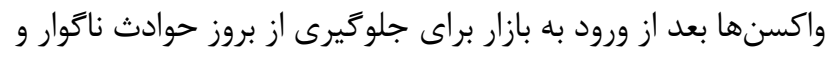

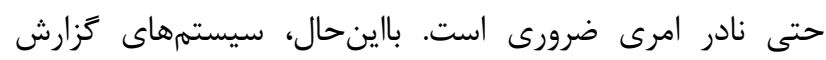

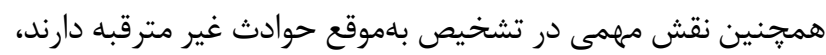

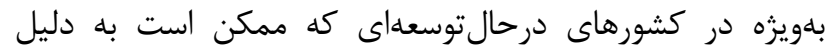
جمعيت بالا، دسترسى به دادههاى الكترونيك يزشكى نداشته باشند.

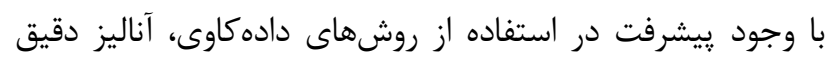

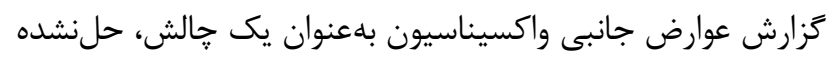

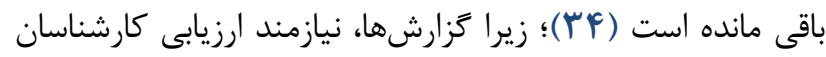

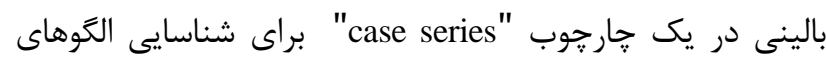

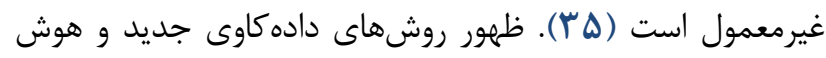

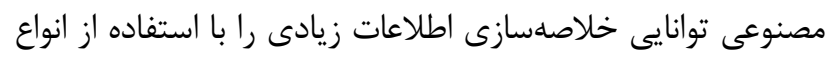

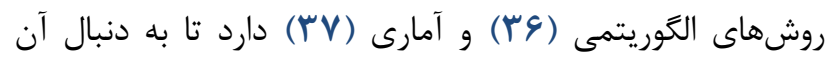
دستيابى به كزارشهاى مشابه و بررسى تخصصى فراهم شود ( بـ،

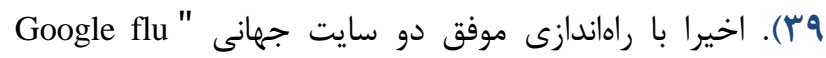
و (/https://www.google.org/flutrends/about) "trends

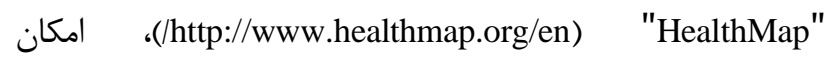
دسترسى به اطلاعات بهداشت عمومى در شناسايى شيوع

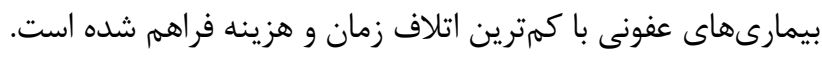

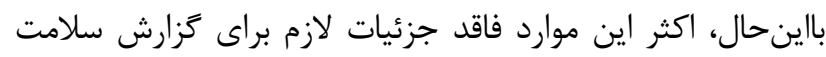

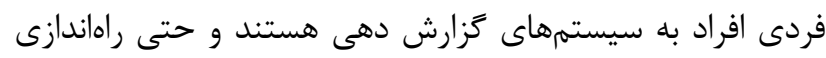
سيستههاى تزارش دهى خودكار نيز، امكان دستيابى به اين إنى

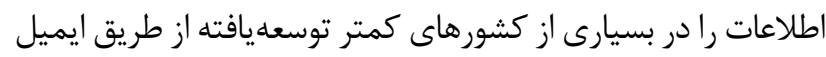

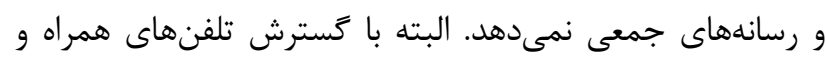

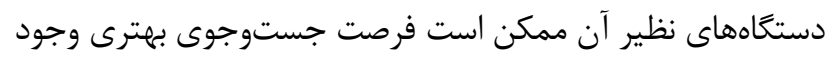

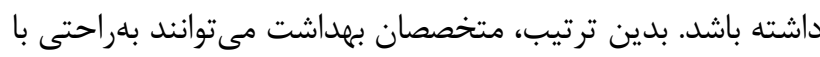
ارسال هشدار عوارض جانبى به مركز نظارت خبر دهند.

ه. تحقيقات Cross-cutting براى بهبود يك برنامةٔ جهانى نظارت

\section{צـ ا ـروشهاى آناليز سود-زيان بالقوه واكسنها}

رويكرد نظارتى به دنبال ايجاد تعادل ميان اثرات مطلوب دارو

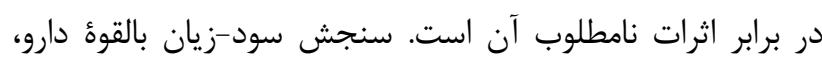

ارزيابىهاى حساس و اختصاصى براى بيشبينى واكنشهاى

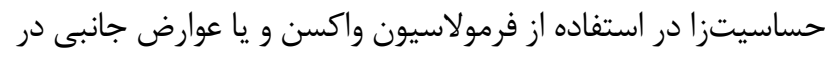
زيرجمعيتها بخصوص جمعيتهاى در معرض خطر (مانند نوزادان) بسيار سودمند است.

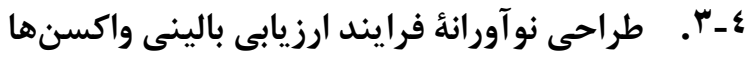
در سالهاى اخير، براى توسعه واكسنهاى جديد طرحهاى مطالعاتى نوآورانهاى براى تأمين نياز فورى بهسرعت درائ تر حال حال ارائه

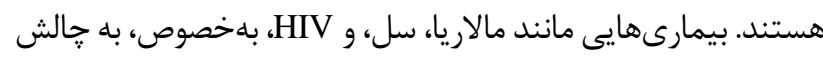

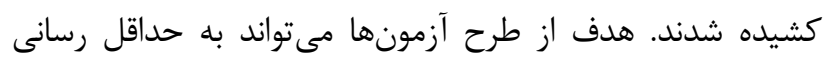

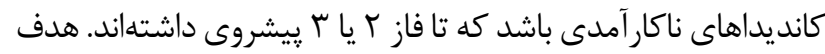

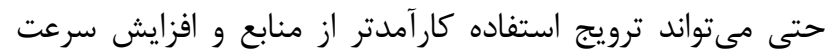

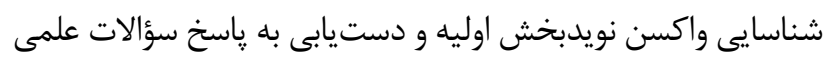

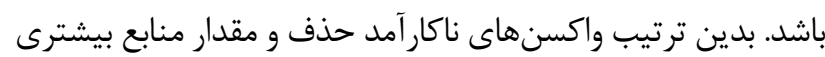
به توسعه واكسن مؤثر اختصاص داده مىشود.

צ ـ . .توسعه مدلهاى رياضى ايمنى زيستى در طول جرخه

$$
\text { توليد واكسن }
$$

يس از ورود واكسن به بازار، رويكرد نظارتى به دنبال

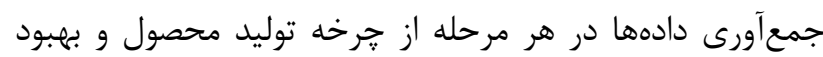

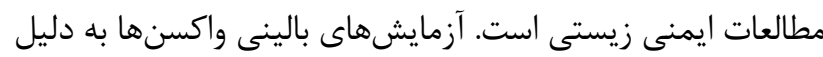

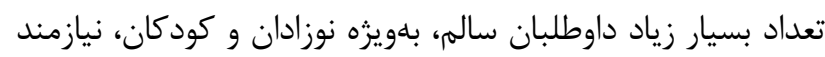
استانداردسازى دقيقترى نسبت به ساير محصولات يزشكى است است

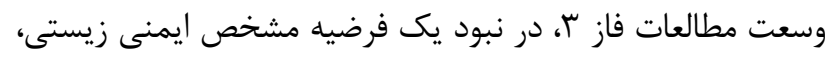

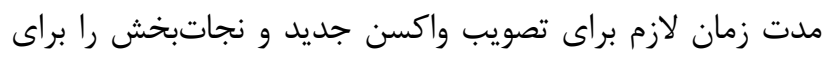

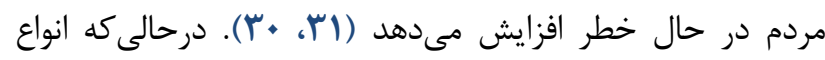

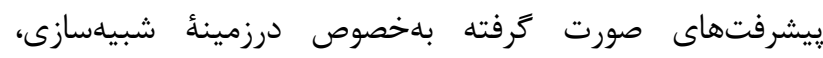
جارجوب مطلوبى را به لحاظ نظرى براى تصميمَيرى مقدار

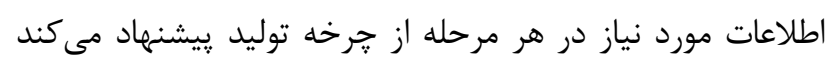

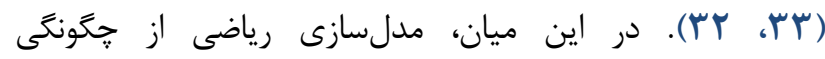

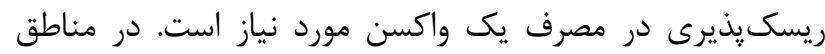

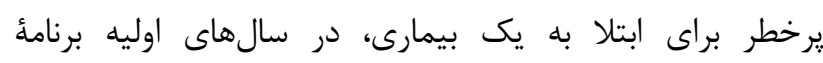

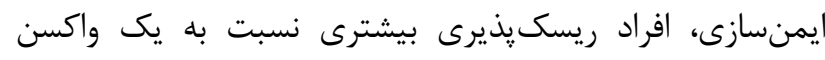

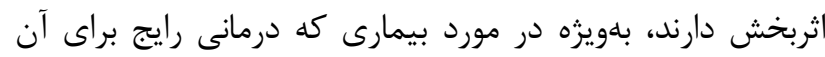

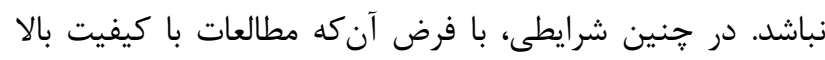

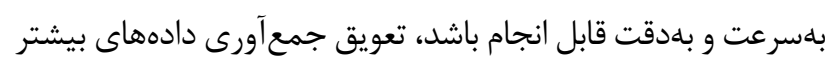

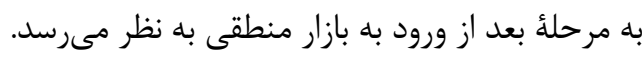


هماهنگ با WHO، نشان داد كه منشأ آن فعاليت رتروويروس اندورن

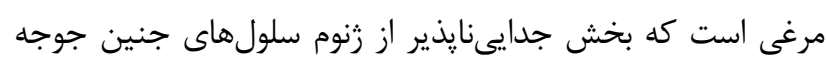

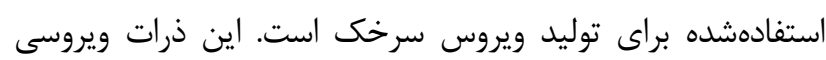

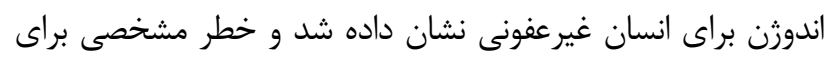

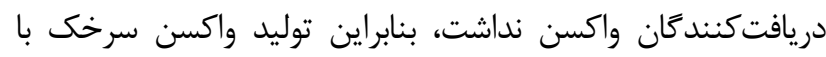

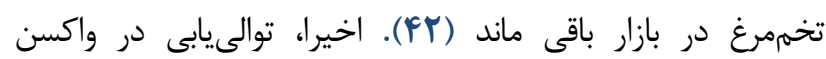

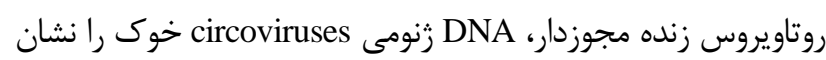
داد (T) (Y). بررسى هاى بعدى مشخص كرد، ترييسين خوكى مورد

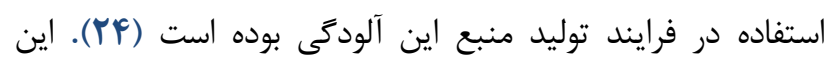

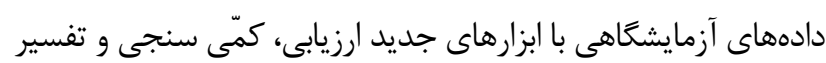

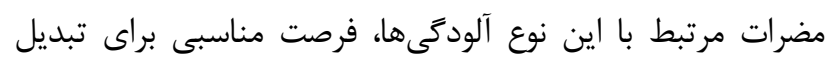

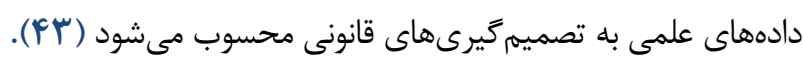

צ-r.ارزش نظارت در حمايت از دسترسى جهانى به

\section{واكسن ايمن و موثر نارت}

\section{\-ـ ـ تحقيقات بر روى فرآيند نظارت}

بسيارى از نظارتها از طريق قانون، مجوز دسترسى شخص

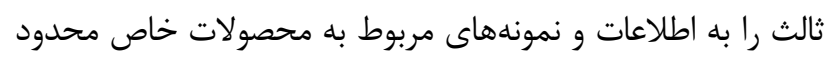

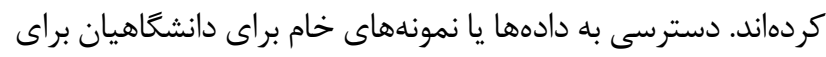

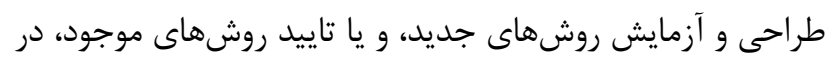

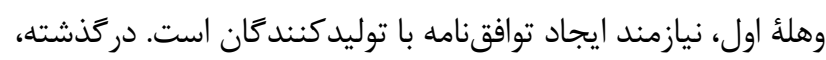

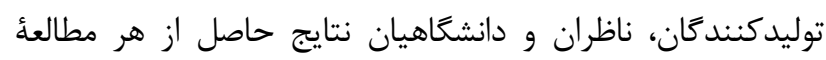

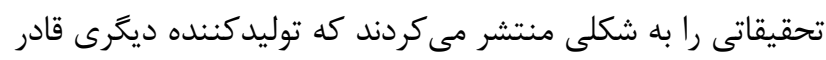

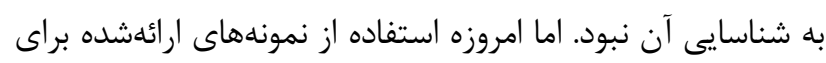

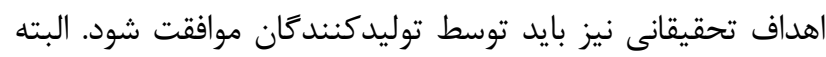

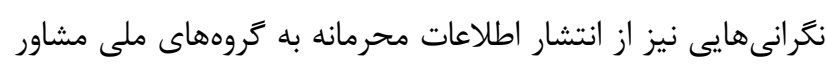

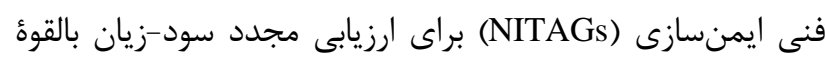

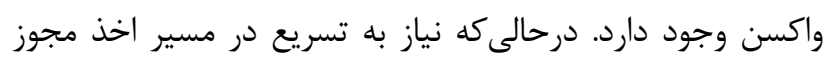

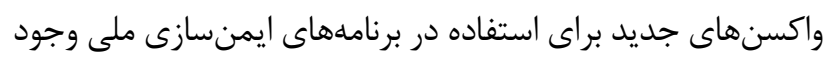
دارد، اما وظايف و مسئوليتهاى نظارت كنند كان و كروههاى مشاى مشاوره در ايمنسازى متفاوت است و بايد بهوضوح مشخص شود (FF-FF).

\section{9. استراتزىهاى ييشنهادى مشترى و و اقدامات حمايتى از دستورالعمل نظارت جهانى}

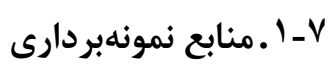

قبل از تصويب تنظيمات نظارت، ابتدا بايد در آزمايشكاههاى تحقيقاتى آناليزها و روشهاى جديد آمادهسازى اعتبارسازى شوند.
فرآيند يِيجيدهاى است زيرا ممكن است اطلاعات جمعآورىشده از

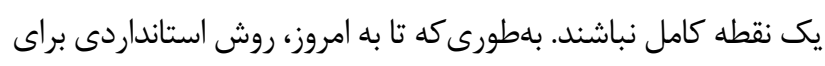

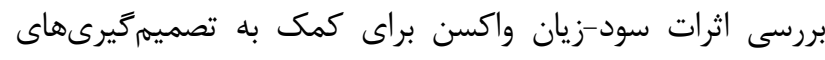

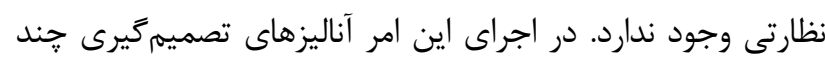

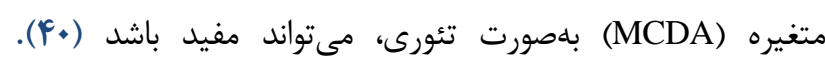

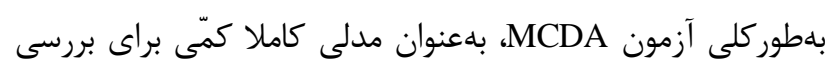

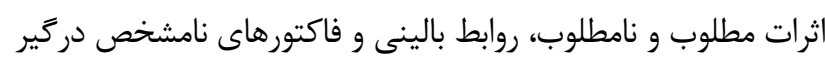

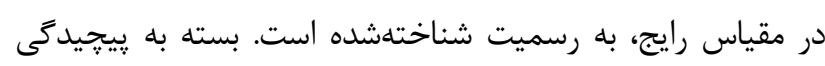

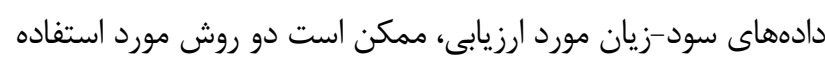

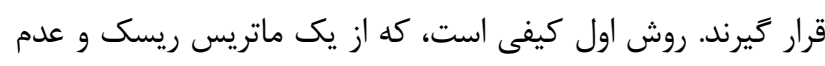

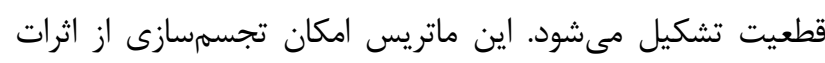

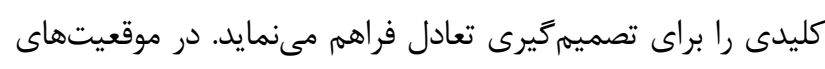

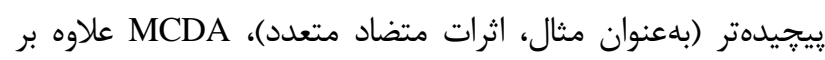

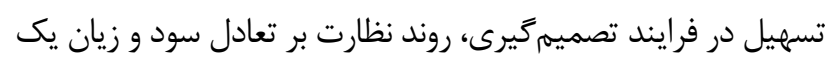

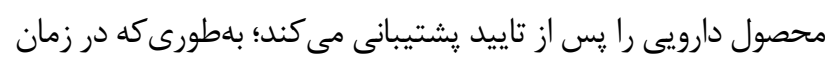

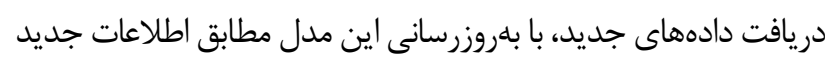

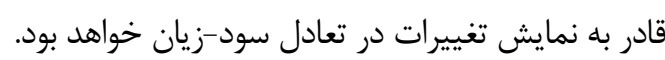

צ-r.بهروز رسانى آناليز سود-زيان بالقوه در طول جرخه

\section{توليد محصول}

اعطاى مجوز نظارت بر يك محصول، نقطه آغاز جرخه توليد

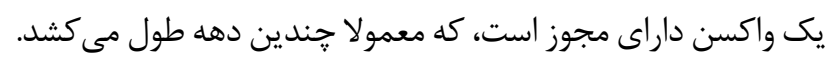

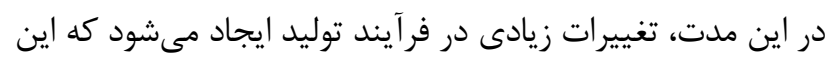

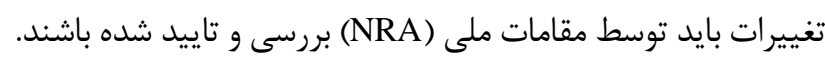

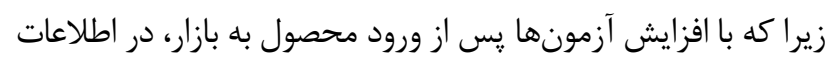

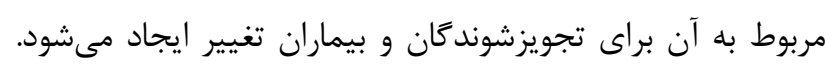

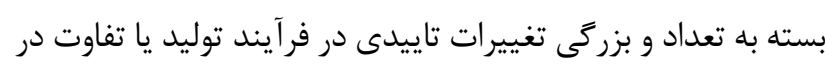

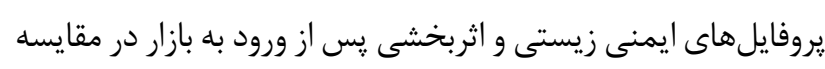

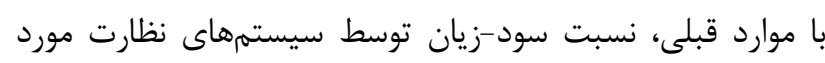

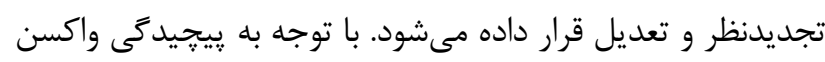

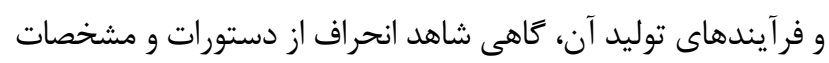

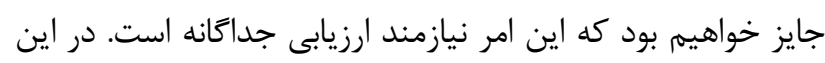

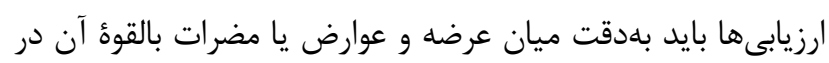
بهداشت عمومى تعادل برقرار شود.

مضرات كشف نشده در زمان اخذ مجوز، براى واكسن (و ديكر

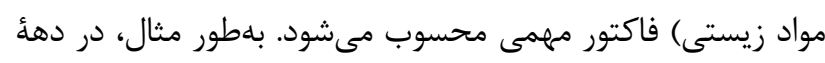

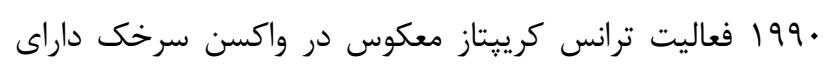

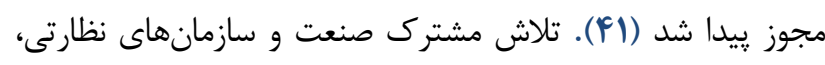


استاندارد اوليه كاليبر مىشود. باينحال، آمادهسازى استانداردهاى ملى يرهزينه است و تخصص انجام اين كار در بسيارى از كشورها

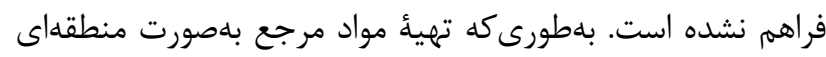

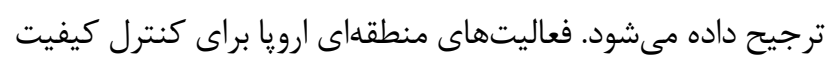

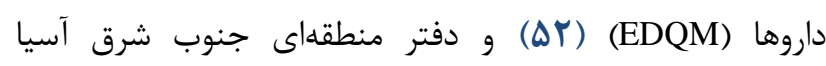

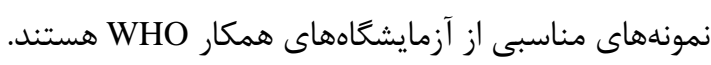
نظارت فعال بر ايمنى زيستى واكسن جديد در كشورهاى كمدر آمد و درحال توسعه فئ بسيارى از كشورها ظرفيت و تجربأ محدودى در اجراى

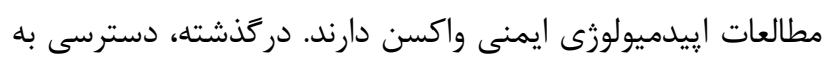
سيستم جامع ارزيابى ايمنى واكسن در ايالات متحده و اتحاديه ارويا

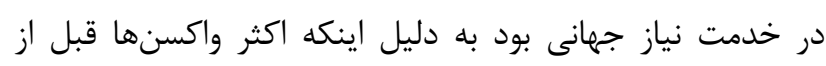

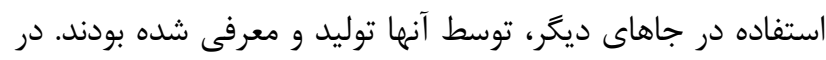

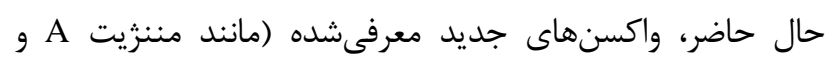

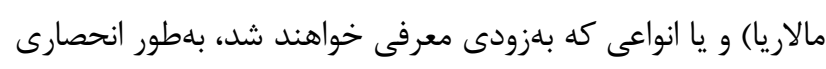

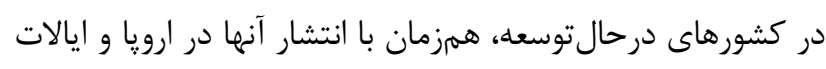

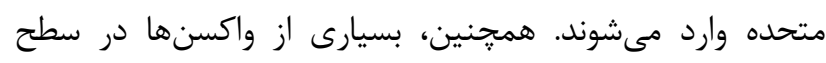

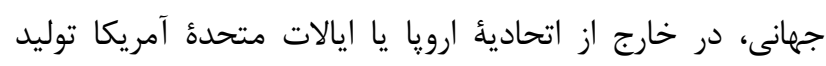

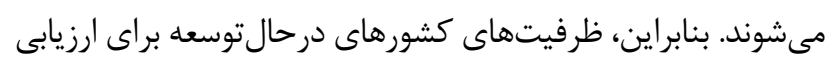

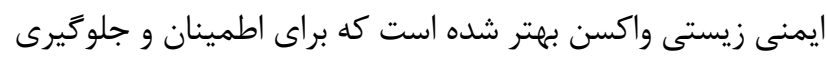

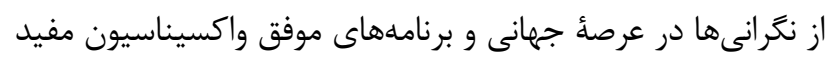

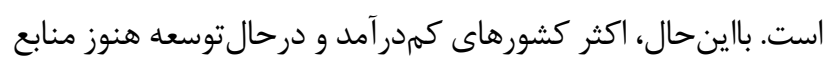

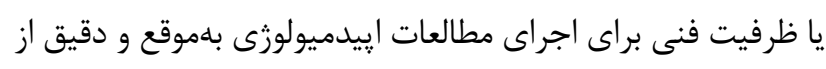

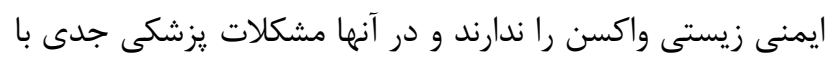

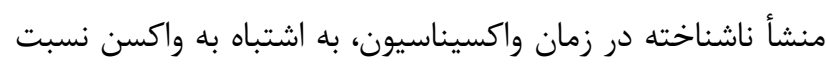

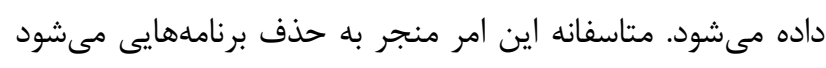

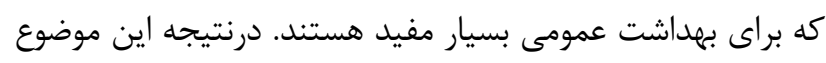

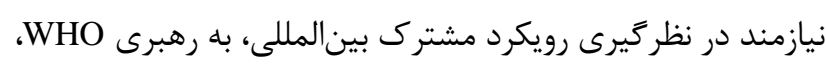

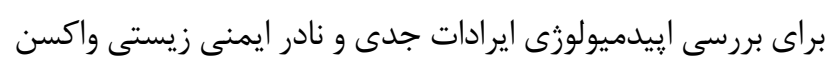

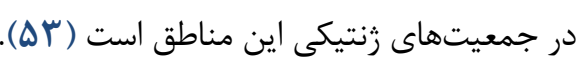

\section{بحث و نتيجه}

در اين مطالعه سعى بر بيان آن بود كه براى ساخت دستور العمل نظارت جهانى بر ايمنى واكسنها از طيف كسترده نظارت و نيان نتايج

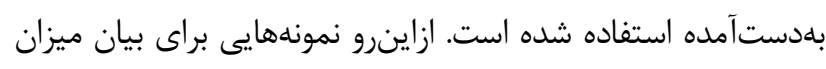

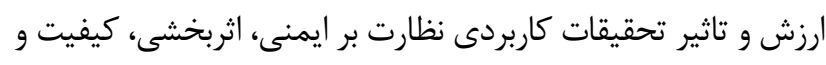

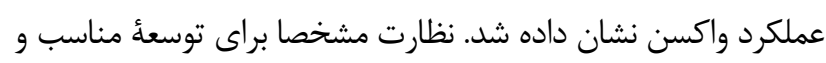

بهكاركيرى انواع نمونه با تفاوت در فرمولاسيون و فرايند توليد

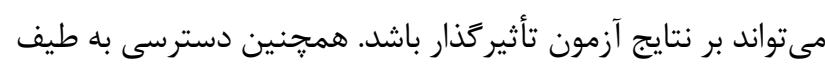

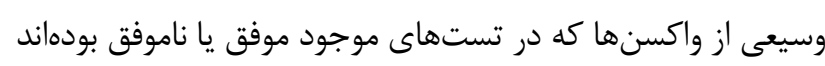
براى ارزيابى روشهاى تست جديد ضرورى است. بلهعنوان مثال،

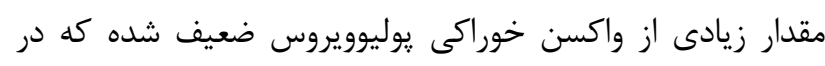

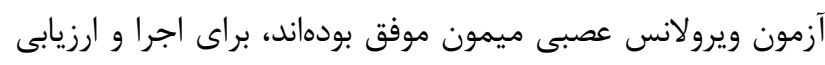

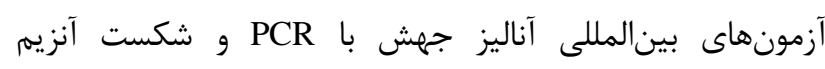

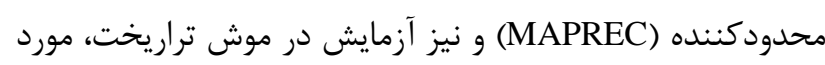

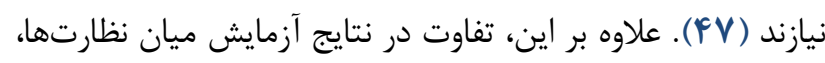

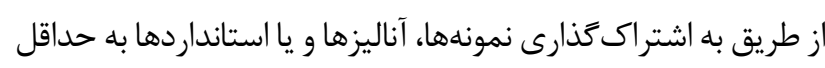

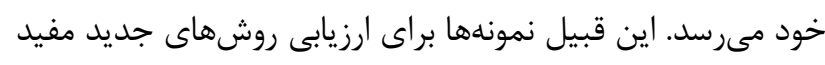

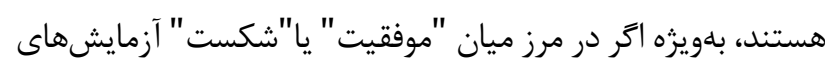

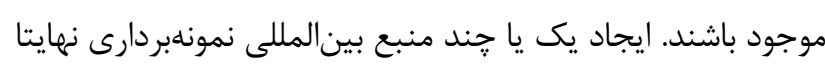

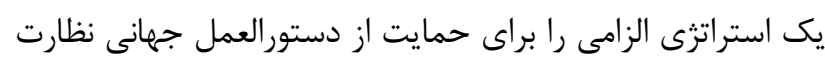

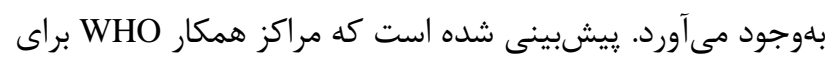

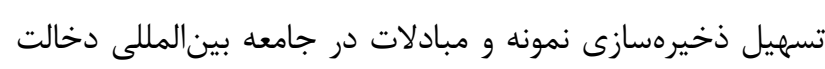

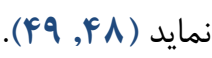

\section{Y Y-V}

محصولات زيستى ازجمله واكسنها، از نظر فعاليت زيستى

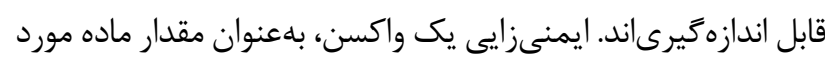

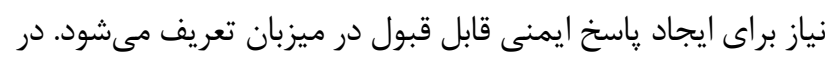

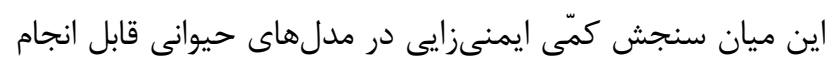

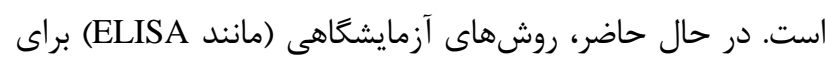

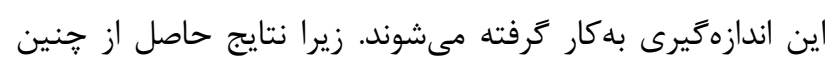

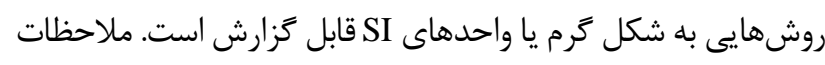

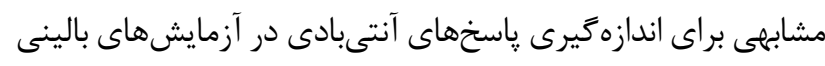

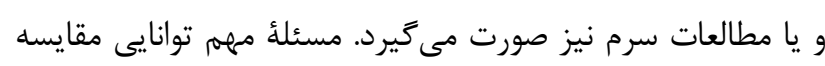

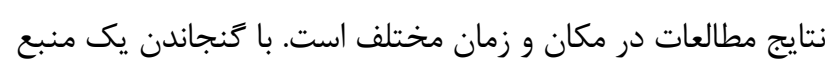

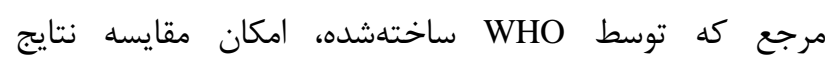

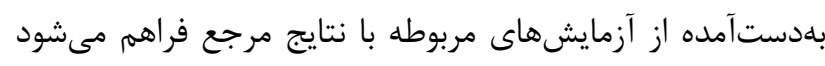

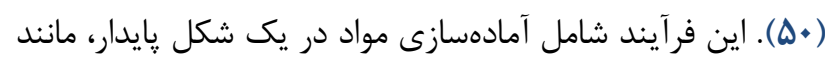

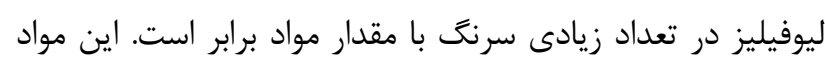

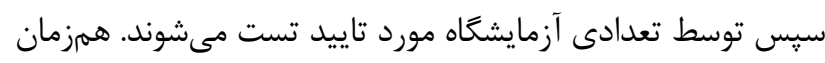

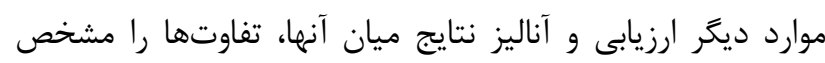

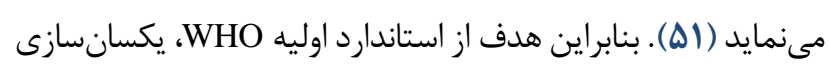

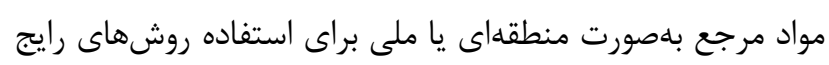

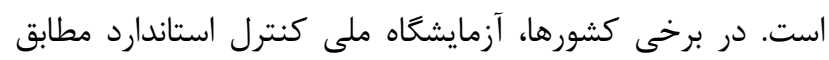




$$
\begin{aligned}
& \text { بالينى بلمنظور سرعت بخشيدن به ارزيابى واكسنهاى جديد } \\
& \text { اميدواربخش، به حداقل رساندن تعداد كانديداهاى غيرموثر در ادامة } \\
& \text { مطالعات فاز بَ و ترويج استفادة موثر از منابع، بسيار مطلوب است } \\
& \text { سياسگزارى } \\
& \text { از آقاى دكتر رسايى كه در طراحى مطالب اين مقاله نقش } \\
& \text { مهمى داشتند، تشكر و قدرانى مىشود. }
\end{aligned}
$$

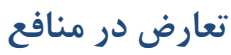

$$
\begin{aligned}
& \text { اين مقاله يزوهشى مستقل است كه بدون حمايت مالى } \\
& \text { سازمانى انجام شده است. در انجام مطالعُ حاضر، نويسندكان مُان } \\
& \text { هيج كونه تضاد منافعى نداشتهاند. }
\end{aligned}
$$

\section{Referance}

1. Nguyen M, Ball R, Midthun K, Lieu TA. The Food and Drug Administration's Post-Licensure Rapid Immunization Safety Monitoring program: strengthening the federal vaccine safety enterprise. Pharmacoepidemiology and drug safety. 2012;21(S1):291-7. [DOI:10.1002/pds.2323] [PMID]

2. Burwen DR, Sandhu SK, MaCurdy TE, Kelman JA, Gibbs JM, Garcia B, et al. Surveillance for GuillainBarre syndrome after influenza vaccination among the Medicare population, 2009-2010. American journal of public health. 2012;102(10):1921-7. [DOI:10.2105/AJPH.2011.300510] [PMID] [PMCID]

3. Destefano F, Vellozzi C. Facilitators Report, Lessons learned exercise, ECDC Vaccine Adverse Event Surveillance and Communication:(VAESCO II) project, Stockholm: European Centers for Disease Control and Prevention. 2009 [cited 2015 August 11].

4. Sangshetti JN, Deshpande M, Zaheer Z, Shinde DB, Arote R. Quality by design approach: regulatory need. Arabian Journal of Chemistry. 2017;10:S3412-S25. [DOI:10.1016/j.arabjc.2014.01.025]

5. Schmeisser F, Vodeiko GM, Lugovtsev VY, Stout RR, Weir JP. An alternative method for preparation of pandemic influenza strain-specific antibody for vaccine potency determination. Vaccine. 2010;28(12):2442-9. [DOI:10.1016/j.vaccine.2009.12.079] [PMID]

7. Hardy S, Eichelberger M, Griffiths E, Weir JP, Wood D, Alfonso C. Confronting the next pandemicworkshop on lessons learned from potency testing of pandemic (H1N1) 2009 influenza vaccines and considerations for future potency tests, Ottawa, Canada, July 27-29, 2010. Influenza and other respiratory $\quad$ viruses. 2011;5(6):438-42.

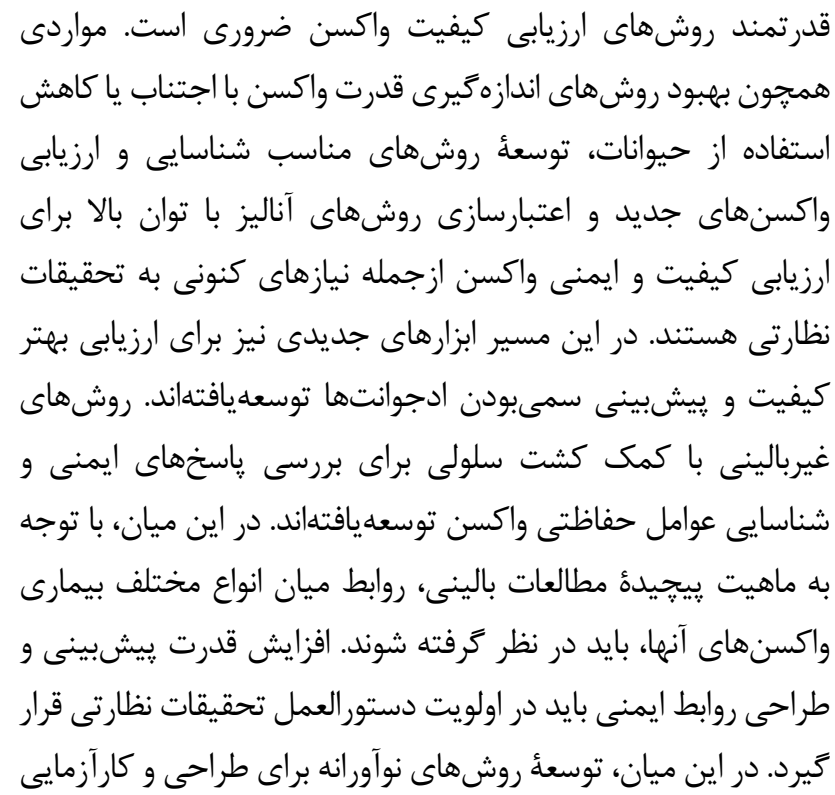

[DOI:10.1111/j.1750-2659.2011.00250.x] [PMCID]

8. Lee M-S, Tseng F-C, Wang J-R, Chi C-Y, Chong P, Su I-J. Challenges to licensure of enterovirus 71 vaccines. PLoS neglected tropical diseases. 2012;6(8):e1737. [DOI:10.1371/journal.pntd.0001737]

[PMID] [PMCID]

9. Mao Q, Li N, Yu X, Yao X, Li F, Lu F, et al. Antigenicity, animal protective effect and genetic characteristics of candidate vaccine strains of enterovirus 71. Archives of virology. 2012;157(1):3741. [DOI:10.1007/s00705-011-1136-3] [PMID]

10. Luo S, Wu F, Ye X, Tao F, Tao J, Luo W, et al. Safety Comparison of Two Enterovirus 71 (EV71) Inactivated Vaccines in Yiwu, China. J Trop Pediatr. 2019. [DOI:10.1093/tropej/fmz004] [PMID]

11. Liang Z, Mao Q, Gao Q, Li X, Dong C, Yu X, et al. Establishing China's national standards of antigen content and neutralizing antibody responses for evaluation of enterovirus 71 (EV71) vaccines. Vaccine. 2011;29(52):9668-74.

[DOI:10.1016/j.vaccine.2011.10.018] [PMID]

12. Slomski A. Vaccines for Enterovirus 71. JAMA. 2014;311(16):1602-. [DOI:10.1001/jama.2014.4453]

13. Mao QY, Liao XY, Xiang YU, Nan LI, Zhu FC, Ying ZE, Liang ZL, Li FX, Wang JZ, Lu FM, Zhuang H. Dynamic change of mother-source neutralizing antibodies against enterovirus 71 and coxsackievirus A16 in infants. Chinese medical journal. 2010 Jul 1;123(13):1679-84.

14. Artaud C, Kara L, Launay O. Vaccine Development: From Preclinical Studies to Phase 1/2 Clinical Trials. Malaria Control and Elimination: Springer; 2019. p. 
$165-76$. [PMID]

[DOI:10.1007/978-1-4939-9550-9 12$]$

15. Cox MM. Recombinant protein vaccines produced in insect cells. Vaccine. 2012;30(10):1759-66. [DOI:10.1016/j.vaccine.2012.01.016] [PMID]

16. Graham BS, Mascola JR, Fauci AS. Novel vaccine technologies: essential components of an adequate response to emerging viral diseases. JAMA. 2018;319(14):1431-2. [DOI:10.1001/jama.2018.0345] [PMID]

17. Gristwood A. Fresh approaches to vaccine development. EMBO reports. 2018;19(8). [DOI:10.15252/embr.201846675] [PMID] [PMCID]

18. Barb AW, Freedberg DI, Battistel MD, Prestegard JH. NMR detection and characterization of sialylated glycoproteins and cell surface polysaccharides. Journal of biomolecular NMR. 2011;51(1-2):163. [DOI:10.1007/s10858-011-9550-0] [PMID] [PMCID]

19. An Y, Cipollo JF. An unbiased approach for analysis of protein glycosylation and application to influenza vaccine hemagglutinin. Analytical biochemistry. 2011;415(1):67-80. [DOI:10.1016/j.ab.2011.04.018] [PMID]

20. Haverland NA, Fox HS, Ciborowski P. Quantitative proteomics by SWATH-MS reveals altered expression of nucleic acid binding and regulatory proteins in HIV1 -infected macrophages. Journal of proteome research. 2014;13(4):2109-19. [DOI:10.1021/pr4012602] [PMID] [PMCID]

21. Onions D, Cote C, Love B, Toms B, Koduri S, Armstrong A, et al. Ensuring the safety of vaccine cell substrates by massively parallel sequencing of the transcriptome. Vaccine. 2011;29(41):7117-21. [DOI:10.1016/i.vaccine.2011.05.071] [PMID]

22. Uhlenhaut C, McClenahan S, Krause PR. Use of DOPPCR in non-specific virus detection. PDA J Pharm Sci Technol. [DOI:10.5731/pdajpst.2011.00842] [PMID]

23. Victoria JG, Wang C, Jones MS, Jaing C, McLoughlin $\mathrm{K}$, Gardner S, et al. Viral nucleic acids in liveattenuated vaccines: detection of minority variants and an adventitious virus. Journal of virology. 2010;84(12):6033-40. [DOI:10.1128/JVI.02690-09] [PMID] [PMCID]

24. Baylis SA, Finsterbusch T, Bannert N, Blümel J, Mankertz A. Analysis of porcine circovirus type 1 detected in Rotarix vaccine. Vaccine. 2011;29(4):6907. [DOI:10.1016/j.vaccine.2010.11.028] [PMID]

25. Gilliland SM, Forrest L, Carre H, Jenkins A, Berry N, Martin $\mathrm{J}$, et al. Investigation of porcine circovirus contamination in human vaccines. Biologicals. 2012;40(4):270-7.

[DOI:10.1016/i.biologicals.2012.02.002] [PMID]
26. Sahoo MK, Holubar M, Huang C, Mohamed-Hadley A, Liu Y, Waggoner JJ, et al. Detection of emerging vaccine-related polioviruses by deep sequencing. J Clin Microbiol. 2017;70(2):2162-5. [DOI:10.1128/JCM.00144-17] [PMID] [PMCID]

27. Zaitseva M, Romantseva T, Blinova K, Beren J, Sirota L, Drane D, et al. Use of human MonoMac6 cells for development of in vitro assay predictive of adjuvant safety in vivo. Vaccine. 2012;30(32):4859-65. [DOI:10.1016/j.vaccine.2012.05.002] [PMID]

28. Grohskopf LA. Prevention and control of seasonal influenza with vaccines. MMWR Recommendations and Reports. 2016;65-70. [DOI:10.15585/mmwr.rr6505a1] [PMID]

29. Wang TT, Palese P. Catching a moving target. Science. 2011;333(6044):834-5.

[DOI:10.1126/science.1210724] [PMID]

30. Ovsyannikova IG, Poland GA. Vaccinomics: current findings, challenges and novel approaches for vaccine development. The AAPS journal. 2011;13(3):438-44. [DOI:10.1208/s12248-011-9281-x] [PMID] [PMCID]

31. Chen RT, Shimabukuro TT, Martin DB, Zuber PL, Weibel DM, Sturkenboom M. Enhancing vaccine safety capacity globally: A lifecycle perspective. Vaccine. 2015;33:46-54 [DOI:10.1016/j.vaccine.2015.06.073] [ [PMCID]

32. Heyse J, Chan I. Review of statistical innovations in trials supporting vaccine clinical development. Statistics in Biopharmaceutical Research. 2016;8(1):128-42.

[DOI:10.1080/19466315.2015.1093540]

33. Ball R, Horne D, Izurieta H, Sutherland A, Walderhaug M, Hsu H. Statistical, epidemiological, and riskassessment approaches to evaluating safety of vaccines throughout the life cycle at the Food and Drug Administration. Pediatrics. 2011;127(1):31-8. [DOI:10.1542/peds.2010-1722F] [PMID]

34. Bauch CT, Bhattacharyya S, Ball RF. Rapid emergence of free-riding behavior in new pediatric immunization programs. PLoS One. 2010;5(9):e12594. [DOI:10.1371/journal.pone.0012594] [ㅍD] [PMCID]

35. Martin D, Menschik D, Bryant-Genevier M, Ball R. Data mining for prospective early detection of safety signals in the Vaccine Adverse Event Reporting System (VAERS): a case study of febrile seizures after a 2010-2011 seasonal influenza virus vaccine. Drug safety. 2013;36(7):547-56. [DOI:10.1007/s40264-0130051-9] [PMID]

36. Chakra CNA, Pariente A, Pinet M, Nkeng L, Moore N, Moride Y. Case series in drug safety. Drug Saf. 2010;33(12):1081-8. [DOI:10.2165/11539300000000000-00000] [PMID] 
37. Hüllermeier E. Case-based approximate reasoning: Springer Science \& Business Media; 2007.

38. Markatou M, Don PK, Hu J, Wang F, Sun J, Sorrentino $\mathrm{R}$, et al. Case-based reasoning in comparative effectiveness research. IBM Journal of Research and Development. 2012;56(5):4: 1-4: 12. [DOI:10.1147/JRD.2012.2198311]

39. Ball R, Botsis T. Can network analysis improve pattern recognition among adverse events following immunization reported to VAERS? Clinical Pharmacology \& Therapeutics. 2011;90(2):271-8. [DOI:10.1038/clpt.2011.119] [PMID]

40. Botsis T, Nguyen MD, Woo EJ, Markatou M, Ball R. Text mining for the Vaccine Adverse Event Reporting System: medical text classification using informative feature selection. Journal of the American Medical Informatics Association. 2011;18(5):631-8. [DOI:10.1136/amiajnl-2010-000022] [PMID] [PMCID]

41. Pratt JW, Raiffa H, Schlaifer R. Introduction to statistical decision theory: MIT press; 1995.

42. Weissmahr RN, Schüpbach J, Böni J. Reverse transcriptase activity in chicken embryo fibroblast culture supernatants is associated with particles containing endogenous avian retrovirus EAV-0 RNA. Journal of Virology. 1997;71(4):3005-12. [DOI:10.1128/JVI.71.4.3005-3012.1997] [PMID] [PMCID]

43. World Health Organization. Reverse transcriptase activity in chicken-cell derived vaccine: WHO consultation, April 1998. Weekly Epidemiological Record= Relevé épidémiologique hebdomadaire. 1998;73(28):209-12.

44. Elmgren L, Li X, Wilson C, Ball R, Wang J, Cichutek $\mathrm{K}$, et al. A global regulatory science agenda for vaccines. Vaccine. 2013;31(1):163-75. [DOI:10.1016/j.vaccine.2012.10.117] [PMID]

45. Duclos P. National Immunization Technical Advisory Groups (NITAGs): guidance for their establishment and strengthening. Vaccine. 2010;28(1):18-25. [DOI:10.1016/j.vaccine.2010.02.027] [PMID]

46. Ricciardi G, Toumi M, Weil-Olivier C, Ruitenberg E, Dankó D, Duru G, et al. Comparison of NITAG policies and working processes in selected developed countries. Vaccine. 2015;33(1):3-11. [DOI:10.1016/j.vaccine.2014.10.035] [PMID]

47. Adjagba A, Senouci K, Biellik R, Batmunkh N, Faye PC, Durupt A, et al. Supporting countries in establishing and strengthening NITAGs: lessons learned from 5 years of the SIVAC initiative. Vaccine. 2015;33(5):588-95.

[DOI:10.1016/j.vaccine.2014.12.026] [PMID]

48. Chumakov KM. Methods to monitor molecular consistency of oral polio vaccine. Poliovirus: Methods and Protocols. 2016:263-77. [DOI:10.1007/978-14939-3292-4_14] [PMID]

49. Marko-Varga Gr, Baker MS, Boja ES, Rodriguez H, Fehniger TE. Biorepository regulatory frameworks: building parallel resources that both promote scientific investigation and protect human subjects. Journal of proteome research. 2014;13(12):5319-24. [DOI:10.1021/pr500475q] [PMID]

50. Graham JE, Borda-Rodriguez A, Huzair F, Zinck E. Capacity for a global vaccine safety system: the perspective of national regulatory authorities. Vaccine. 2012;30(33):4953-9.

[DOI:10.1016/j.vaccine.2012.05.045] [PMID]

51. Yu YB, Taraban MB, Wang W, Briggs KT. Improving biopharmaceutical safety through verification-based quality control. Trends Biotechnol. 2017;35(12):114055. [DOI:10.1016/j.tibtech.2017.08.010] [PMID]

52. Zimmer J, Vieths S, Kaul S. Standardization and regulation of allergen products in the European :union: Current allergy and asthma reports. 2016;16(3):21. [DOI:10.1007/s11882-016-0599-4] [PMID]

53. Commission EP, Medicines EDftQo, Healthcare. European pharmacopoeia: Council of Europe; 2010.

54. Cruz-Aponte M. Metapopulation and Non-proportional Vaccination Models Overview. Advances in the Mathematical Sciences. 2016,1(3):187-207888. [DOI:10.1007/978-3-319-34139-2_8] 